\title{
Early life history of the daubed shanny (Teleostei: Leptoclinus maculatus) in Svalbard waters
}

\author{
C. A. Meyer Ottesen • Haakon Hop • \\ Jørgen Schou Christiansen • Stig Falk-Petersen
}

Received: 2 June 2010 /Revised: 3 December 2010 / Accepted: 13 December 2010 /Published online: 23 February 2011

(C) The Author(s) 2011. This article is published with open access at Springerlink.com

\begin{abstract}
The daubed shanny (Leptoclinus maculatus, Family Stichaeidae) is considered to be an ecologically significant species in the arctic waters of Norway because of high abundance and the unique energy storage abilities of its postlarvae. Both postlarvae and adults are found in relative large abundances in Svalbard fjords as well as along the ice edge of north-east Svalbard, even at sub-zero temperatures. The postlarva feeds primarily on Calanus spp. and stores lipids from this high-energy diet in a unique lipid sac on the ventral side of its body. This energy storage enables it to survive pelagically during the arctic winters when food is scarce. The postlarvae are pelagic for the first 2-3 years of their life before they descend to the bottom and transform to a benthic mode of life. Our results indicated that this transition takes place when the postlarva reach about $80 \mathrm{~mm}$ in length and an age of 3 years. The relative size of the lipid sac, as well as changes in the morphology of the postlarvae, can be used as indices of the transition from pelagic postlarva to benthic juvenile. The lipid sac index (\% of gutted weight) was negatively correlated with length and age and started to decrease when the postlarva transformed to a benthic lifestyle. At this point, the growth in terms of the length-weight
\end{abstract}

This article belongs to the special issue "Marine Biodiversity under Change".

C. A. Meyer Ottesen $(\triangle) \cdot$ J. S. Christiansen

Department of Arctic and Marine Biology-BFE,

University of Tromsø,

9037 Tromsø, Norway

e-mail: camilla.ottesen@uit.no

H. Hop $\cdot$ S. Falk-Petersen

Norwegian Polar Institute,

Fram Centre,

9296 Tromsø, Norway relationship shifted from a positive asymptotic growth to a negative asymptotic growth, reflecting the changes in the lipid sac index, while several changes in morphological traits took place. The benthic mode of early juveniles is largely influenced by environmental conditions and prey abundance, since the fish is depleted from their energy stores and need to rapidly switch to benthic prey in their new habitat. In conclusion, this is the first study on the early life history of the daubed shanny and it presents evidence that the first 5 years in the life of this species is divided in two distinct parts, one pelagic and one benthic, in which postlarvae display unique growth and morphological traits adapted to the challenges of these arctic marine environments.

Keywords Leptoclinus maculatus · Postlarva . Lipid storage - Adaptability to high arctic waters .

Early life history $\cdot$ Morphology

\section{Introduction}

The daubed shanny (Leptoclinus maculatus) Fries, 1838, is one of three teleost fish species in the family Stichaeidae (Gill 1864) that are commonly found in the arctic waters. In the Barents Sea, they are distributed from the polar front and northwards (Byrkjedal and Høines 2007). Unlike their southern relatives, the arctic stichaeids have evolved several physiological and biochemical adaptations that enable them to survive sub-zero temperatures and prolonged periods of food shortage. Among these are the synthesis of antifreeze proteins (C. Ottesen, unpublished data) and a unique lipid sac in postlarval fish which may store large amounts of dietary lipids (Falk-Petersen et al. 1986). The lipid sac is situated on the ventral part of the body under the gut and 
runs from the pectoral fins to the anal opening. It consists of closely packed lipid vacuoles of different sizes which are surrounded by a simple membrane. The lipids are mainly triacylglycerols $(80 \%)$ and phospholipids (18\%) (Murzina et al. 2008, 2010), and fatty acid signatures originate from feeding on Calanus spp. Although the role of lipid accumulation in buoyancy control of fishes is well known (Clarke et al. 1984; Phleger 1998), Falk-Petersen et al. (1986) concluded that the lipid sac of L. maculatus is primarily an energy storage organ and that its role in buoyancy control is of minor importance. The lipid sac enables the postlarvae to take full advantage of the high secondary production in the arctic summer and store sufficient energy to meet metabolic requirements during periods of food shortage in winter. Furthermore, $L$. maculatus has a lipid content in the flesh of approximately $40 \% \mathrm{dw}$ (dry weight) (Falk-Petersen et al. 1986). The lipid sac, together with the energy-rich muscle tissue, obviously represents important adaptations for larval L. maculates to sustain itself in a seasonally variable and extreme arctic marine environment. The pelagic postlarvae are abundant and constitute a valuable food item for predatory fishes, e.g. Atlantic cod (Gadus morhua) and polar cod (Boreogadus saida) (C. Ottesen, unpublished data), sea birds, e.g. common guillemot (Uria aalge) (Watanuki et al. 1992) and Atlantic puffin (Fratercula arctica) (Barrett 2002), and seals, e.g. ringed seal (Phoca hispida) (Labansen et al. 2007) and harp seal (Phoca groenlandica) (Nilssen and Lindstrøm 2005). As such, they are a valuable component in the transfer of energy from Calanus spp. to higher trophic levels in the arctic marine ecosystem of Svalbard.

Leptoclinus maculatus has a circumpolar distribution between latitudes $79^{\circ} \mathrm{N}$ and $43^{\circ} \mathrm{N}$ (http://www.fishbase.org) and two sub-species have been recognised with $L . m$. diaphanocarus in the Pacific Ocean and L. m. maculatus in the Atlantic Ocean (Mecklenburg and Sheiko 2004). Leptoclinus maculatus is a small-sized species with a maximum length of $\sim 200 \mathrm{~mm}$, but rarely more than $160 \mathrm{~mm}$ (Andriyashev 1954). Both postlarvae and adults are found in relatively high numbers along the ice edge and in the fjords of west and north-east Svalbard. In the Barents Sea and Svalbard waters, L. maculatus are found at low temperatures $\left(-1.6\right.$ to $\left.2.0^{\circ} \mathrm{C}\right)$ and high salinities $(33-35 \%$ ) (Andriyashev 1954). In the north Atlantic, L. maculatus probably spawns demersally in shallow waters during winter (Pethon 2005). However, the exact times of spawning and hatching are unknown as eggs and prolarval stages have not been reported. It is not known if $L$. maculatus prolarva has a yolk sac stage where the yolk sac is later transformed to the lipid sac, or if they hatch with the lipid sac as an energy supply instead of a yolk sac. Leptoclinus maculatus has a relatively low fecundity $(\leq 1,000$ eggs) (Andriyashev 1954; Pethon 2005) and quite large eggs of
$1.50 \mathrm{~mm}$ in diameter (Christiansen et al. 1998). Leptoclinus maculatus probably exhibits parental care as has been reported for several species within the Stichaeidae family (Baylis 1981; Gross and Shine 1981). The life history of $L$. maculatus comprises a pelagic phase of early postlarvae, and a benthic phase of late postlarvae, juveniles and adults that live on soft bottoms from 15 to $400 \mathrm{~m}$ depth (Pethon 2005), and in the Barents Sea from 50 to $240 \mathrm{~m}$ depth (Andriyashev 1954). Arctic fishes are limited to cold waters and a relative narrow temperature range and, therefore, they are considered particularly vulnerable to climate change (Rose 2005).

In this study, we examined the body morphometrics and pigmentation, growth (i.e. body size-at-age and body weight-length relationships), and lipid sac indices (LSI) of postlarval L. maculatus. Based on these characters, we describe four postlarval stages which are either entirely pelagic or display a transitional phase between a pelagic and benthic mode of life.

\section{Materials and methods}

\section{Sampling of fishes}

Daubed shanny were sampled in the Svalbard fjord and shelf areas (Fig. 1) during several cruises in 2006-2008

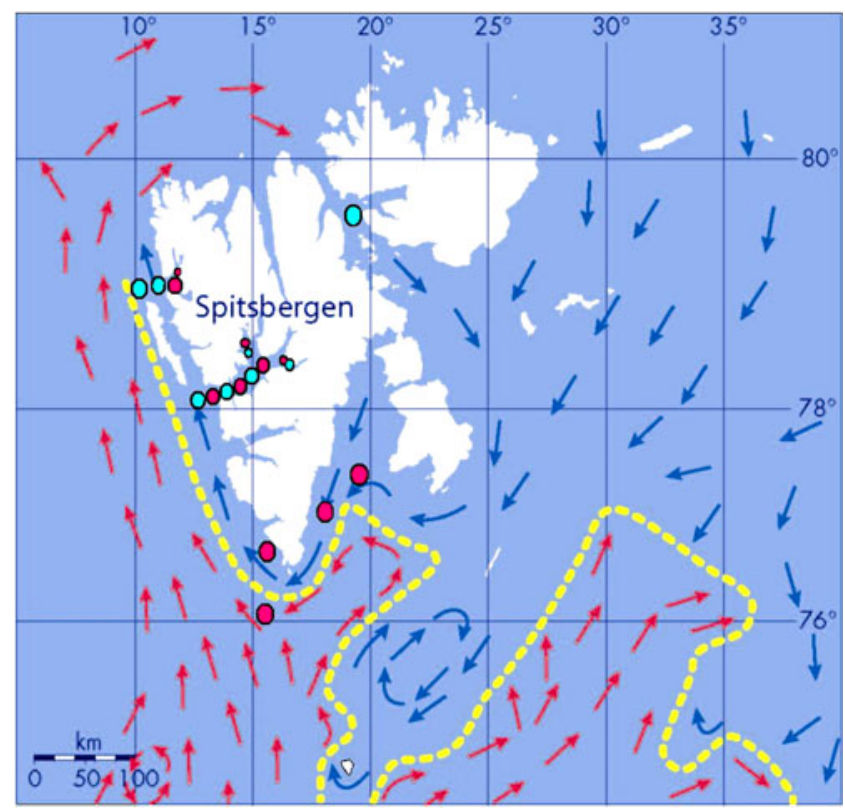

Fig. 1 Sampling areas and water masses around Svalbard. Both pelagic and bottom trawls were used at all sampling areas. The turquoise dots represent sampling areas where postlarvae were obtained in the pelagic trawl, while the pink dots represent those areas where postlarvae were obtained in the bottom trawl. The blue and red arrows indicate Arctic and Atlantic waters, respectively. The yellow line shows the polar front (modified from Sakshaug et al. 1994) 
(April, May, July, August, September and October) with R/V Jan Mayen, University of Tromsø. Pelagic postlarvae were sampled in the water column by a Harstad trawl with an opening of $11 \times 40 \mathrm{~m}$ and $40-\mathrm{mm}$ mesh size (towing speed $\sim 3$ knots for $\sim 45 \mathrm{~min}$ at depths 50-100 m). Benthic postlarvae were sampled on soft bottoms (mud, clay or silt) by a Campelen 1800 shrimp trawl (mesh size $\sim 10 \mathrm{~mm}$, towing speed $\sim 3 \mathrm{knots}$ ) for $\sim 20 \mathrm{~min}$ at depths of 150 $400 \mathrm{~m}$. Both gears were used at all sampling stations. The specimens were immediately frozen $\left(-40^{\circ} \mathrm{C}\right)$ in labelled plastic zip-bags for subsequent laboratory analyses at the University of Tromsø and the Norwegian Polar Institute.

\section{Analyses of postlarvae}

The sampled specimens fitted well with the definition of postlarval fishes given by Hubbs (1943), i.e. "larvae following the time of absorption of yolk; applied only when the structure and form continues to be strictly unlike that of a juvenile" (a juvenile is "essentially similar to adult"). Postlarvae of three stichaeid species, i.e. daubed shanny (Leptoclinus maculatus), snakeblenny (Lumpenus lampretaeformis) and stout eelblenny (Anisarchus medius) were represented in the samples. The postlarvae were diagnosed to species using the descriptions of Fahay (n.d.), Andriyashev (1954) and Mecklenburg and Sheiko (2004), and a total of 72 specimens of Leptoclinus maculatus were subjected to further analyses (Table 1).

Single specimens were examined for patterns of pigmentation. The caudal length ( $\mathrm{mm})$ was measured using a translucent ruler on a white background. Morphometric distances (Fig. 2) were measured by a digital calliper $(0.01 \mathrm{~mm})$, i.e. head length, depth of head, depth of body at anal opening, depth of caudal peduncle, length from head to anal fin, length from head to dorsal fin, length of anal, dorsal and caudal fins, interorbital space, length and width of eye, length of snout and width of jaw. The morphometric distances are expressed as \% of caudal length (CL) to eliminate scaling effects. Intact specimens were weighed $(0.01 \mathrm{~g})$. The lipid sac was carefully dissected over a weighing ship to avoid loss of lipid droplets and weighed $(0.001 \mathrm{~g})$, and the guts were removed before weighing the

Table 1 Number of postlarval daubed shanny (Leptoclinus maculatus) from each habitat analysed in this study

\begin{tabular}{llll}
\hline Stage & Pelagic & Benthic & Total \\
\hline L2 & 20 & 0 & 20 \\
L3 & 24 & 0 & 24 \\
L3 & 5 & 13 & 18 \\
L5 & 5 & 5 & 10 \\
Total & $\mathbf{5 4}$ & $\mathbf{1 8}$ & $\mathbf{7 2}$ \\
\hline
\end{tabular}

remaining part, i.e. gutted weight $(0.01 \mathrm{~g})$. The Lipid Sac Index (LSI) was defined as: (weight of lipid sac/gutted weight $) \times 100 \%$, i.e. percentage of gutted weight. Finally, the otoliths were removed, cut in half and cleared in glycerol before age readings by a Leica $M Z G$ stereo microscope (magnification $\times 2.0-4.0$ ). The interpretation of the annuli was done according to the procedures described by C.A.R.E. (Committee of Age Reading Experts) (2000). Only 2 intact specimens of the L1 stage were obtained and these were therefore excluded from most measurements and all statistical analyses and are thus not included in Table 1. However, we will give a description of the L1 stage in terms of size, pigmentation and lipid sac.

Data treatments

All statistical treatments and graphical presentation of the data were done in SYSTAT12 (2007 version). As no differences could be found between sampling areas and seasons, data were pooled for analyses. Based on the result of the length distribution of postlarvae, two size-groups were identified: one pelagic consisting mostly of L2 and L3 stages and one transitional consisting of L4 and L5 stages (see "Results"). Rather than using the individual postlarval stages, these groups were used to describe the length-weight relationship and growth of postlarvae. Thus, postlarva stages were pooled into these two groups in these descriptions. A linear regression module was applied for analysing the length-weight relationship and growth of postlarval groups. Log gutted weight and log caudal length were used in the linear regression module. One outlier was removed from the analysis so that the results represent the majority of each postlarval group. These results were tested for significance using ANCOVA. Morphological differences between postlarval stages and postlarval groups were determined by discriminant analysis, with the complete model. Each morphological measurement was tested using Kruskal-Wallis for postlarval stages and two-sample $t$ test for postlarval groups.

\section{Results}

Description of postlarval stages

Five postlarval stages were recognised based on caudal length, size of lipid sac and pigmentation (Fig. 3). These stages are not set and defined as part of the physiological development of the postlarva and are not described in existing literature. However, they were useful as they represented specific groupings in size, habitat, size of lipid sac and pigmentation of the postlarval material. All postlarval stages except L5 shared one feature: a row of melanophores along the gut, surrounding the lipid sac, and 
Fig. 2 The morphometric distances used to describe $L$. maculatus postlarvae. Body measurements: caudal length, pre-dorsal- and pre-anal length, length of the dorsal, anal and caudal fins, depth of the body at anal opening and depth of the caudal peduncle. Head measurements: depth of the head at mid-orbit, length of the head, length and width of the eye through mid-orbit and length of the snout, interorbital space and width of the lower jaw (measured at midpoint of the jaw) a

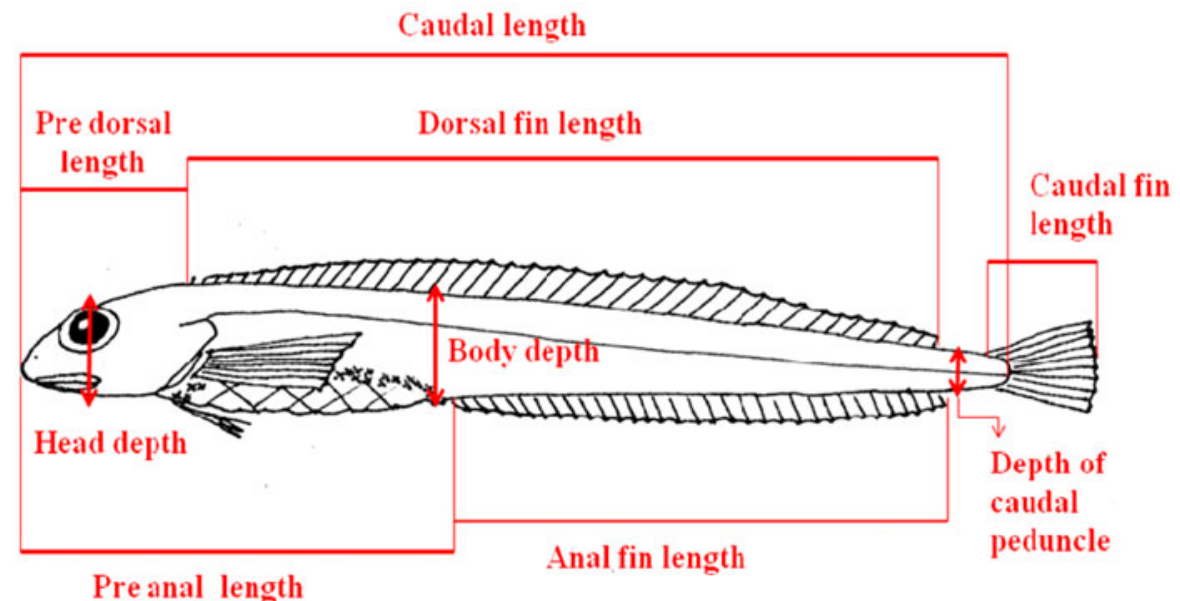

b

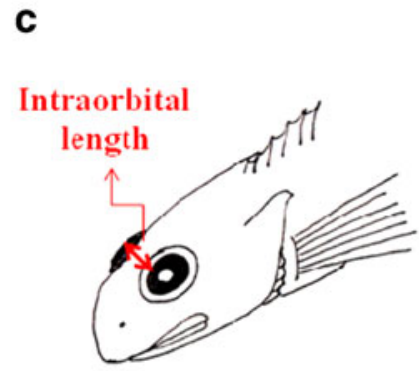

d

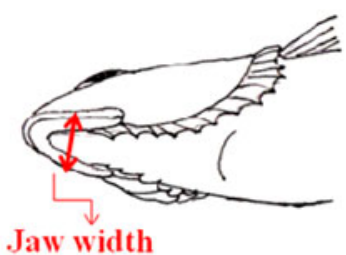

along the anal fin base. Except for this, each stage had a distinct pigmentation. The L1-L3 stages were only found in the pelagic and all had a distinct lipid sac. The L1 specimens were $<50 \mathrm{~mm}$ in length and $0-1$ years of age.

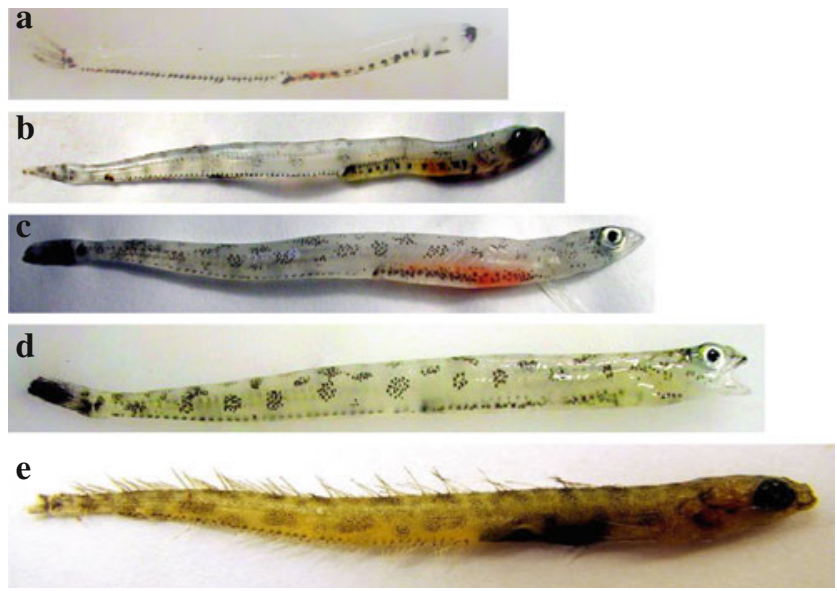

Fig. 3 Postlarval stages of Leptoclinus maculatus. a L1: CL $<50 \mathrm{~mm}$, age $\approx 0-1$ years, body translucent, lipid sac present, pelagic (not processed further in this study); b L2: CL: $40-56 \mathrm{~mm}$, age: 1-2 years, body translucent with few melanophores, lipid sac present, pelagic; c) L3: CL: 45-76 mm, age: 2-3 years, body white- translucent with melanophores, lipid sac present, pelagic; d L4: CL: 65-99 mm, age: 25 years, body light yellow with melanophores, lipid sac present, pelagic and benthic; e L5: CL: 74-100 mm, age: 2-5 years, color of body like adults, lipids exhausted, only remains of lipid sac membranes, pelagic and benthic
The body was translucent with a single row of melanophores along the gut and anal fin. The L1 stage was not analysed further in this study as too few intact specimens were obtained. The L2 stage was $40-56 \mathrm{~mm}$ in length and 1-2 years of age. These specimens were also translucent, but with two rows of dark spots, one just below and one just above the lateral line, created by melanophores grouped closely together. The caudal fin also had melanophores that formed dark spots. The L3 stage resembled the L2 stage but with a white, translucent body, more distinct spots and a black caudal fin, and the lipid sac often had an orange colour. The specimens were $45-76 \mathrm{~mm}$ in length and 23 years of age. The L4 specimens were found both in the pelagic and the benthic habitats. They were $65-99 \mathrm{~mm}$ in length and 2-5 years of age. The body was more pigmented than that of L3, most often light yellow with distinct black spots and a black-tipped caudal fin. The lipid sac (Fig. 4) was always present, but varied greatly in size from small and nearly exhausted to larger and full of lipids. The L5 specimens were found both in pelagic and benthic habitats. They were $74-100 \mathrm{~mm}$ in length and 2-5 years of age with a coloration like that of adult specimens. The lipids were exhausted and only the lipid sac membranes remained. Thus, L5 together with L4 should be considered transitional stages between a pelagic and a benthic mode of life. Table 1 shows the habitats in which each postlarval stage, except L1 (strictly pelagic), was found. 


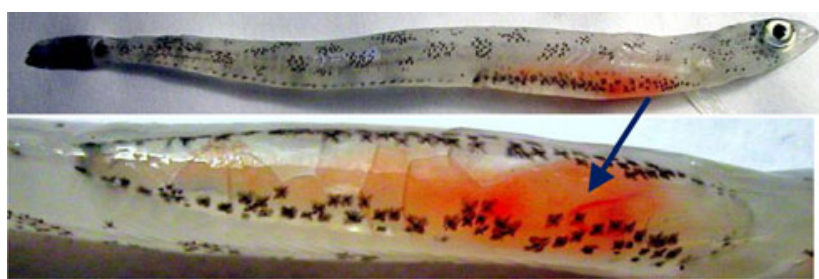

Fig. 4 The lipid sac of L. maculatus postlarva (L3 stage). The lipid sac is situated on the ventral part of the body below the gut and runs from the pelvic fins to the anal opening. It is lined with clusters of melanophores. The orange color is likely from the carotenoides of dietary Calanus spp

Length and age distribution according to habitat

The postlarvae had a length span of 45-100 $\mathrm{mm}$ and an age span of 1-5 years. Length and age distributions of postlarvae differed between pelagic and benthic habitats. The pelagic specimens were smaller and younger than the benthic specimens (Fig. 5). The mean length of pelagic specimens was $59 \mathrm{~mm}$ and of benthic specimens $89 \mathrm{~mm}$ (two-sample $t$ test, $p<0.001$ ), while the mean age was 2.4 years for pelagic specimens and 3.2 years for benthic specimens (two-sample $t$ test, $p<0.001$ ). Although the age distribution was quite even with a peak at 2-3 years of age, specimens between $61-71 \mathrm{~mm}$ in length were absent (only one specimen was found) resulting in two peaks in the length distribution: one between $40-60 \mathrm{~mm}$ and one between $70-100 \mathrm{~mm}$. Thus, two size-groups were identified (Fig. 5). The 'Pelagic group' consisted mostly of stages L2-L3 with a length-span of 45-69 $\mathrm{mm}$ and was predominately pelagic. The 'Transitional group' consisted of stages L4-L5 with a length-span of 70-100 mm and was found both in pelagic and benthic habitats. Thus, we identify one group as pelagic postlarvae (stages L2-L3) living off the energy storage of their lipid sac. The second group had varying size of the lipid sac; some had a large lipid sac while others had exhausted their lipids and the lipid sac was starting to be absorbed by their body. Therefore, the second group was identified as a transitional group (stages L4-L5) of specimens that was ready for the transition between the pelagic life stage and the benthic life stage.

\section{Size-at-age and LSI of postlarval stages}

Caudal length and gutted weight varied with age for the different postlarval stages (Fig. 6). Most of the L2 and L3 specimens were 2 years of age, $<60 \mathrm{~mm}$ long (Fig. 6a) and $<0.5 \mathrm{~g}$ in weight (Fig. 6b). This resulted in an aggregation of most of these specimens into a dense cluster, while L4 and L5 were scattered more evenly through the size and age ranges (Fig. 6).

Length increased moderately for 1-2 years, and then a sharp increase in length was apparent when the post-
Fig. 5 Length $(\mathbf{a}, \mathbf{b})$ and age (c, d) distribution of

L. maculatus postlarval stages found in pelagic and benthic habitats. The two uppermost figures $(\mathbf{a}, \mathbf{c})$ represent the pelagic specimens while the two figures below $(\mathbf{b}, \mathbf{d})$ represent the benthic specimens. The length distribution of L. maculatus postlarvae indicated two length groups: Pelagic group (red) consisted mostly of stages L2-L3 and represented a size-range of 45-69 $\mathrm{mm}$. Thus, the one benthic L4 specimen of $67 \mathrm{~mm}$ is included in the Pelagic group. Transitional group (blue) consisted mostly of stages L4-L5 and represented a length range of $70-100 \mathrm{~mm}$

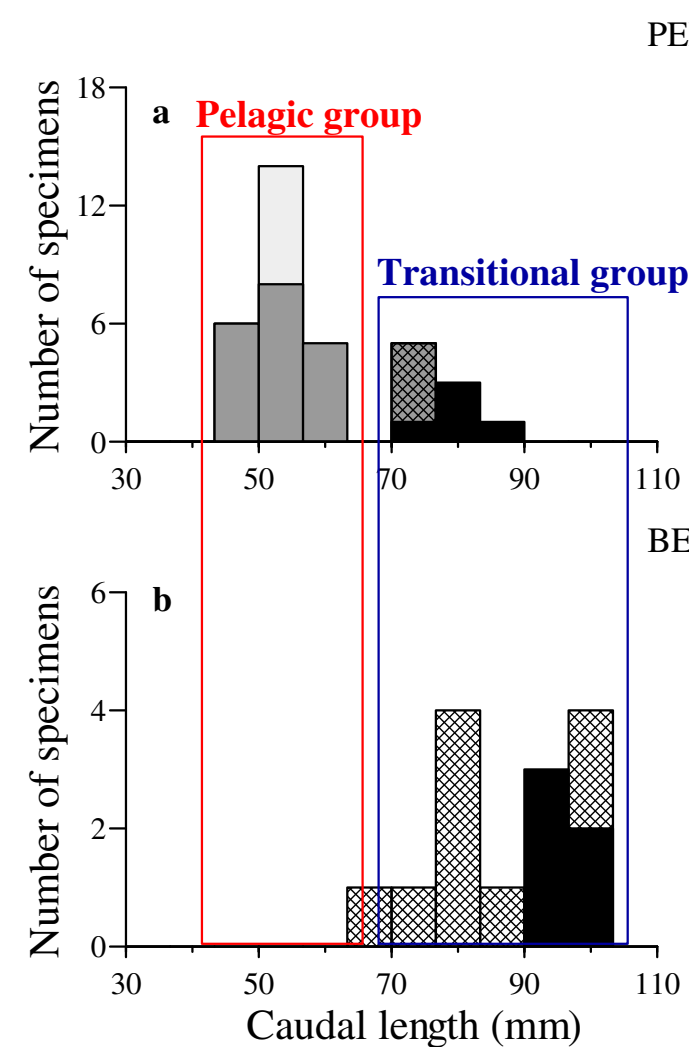

PELAGIC
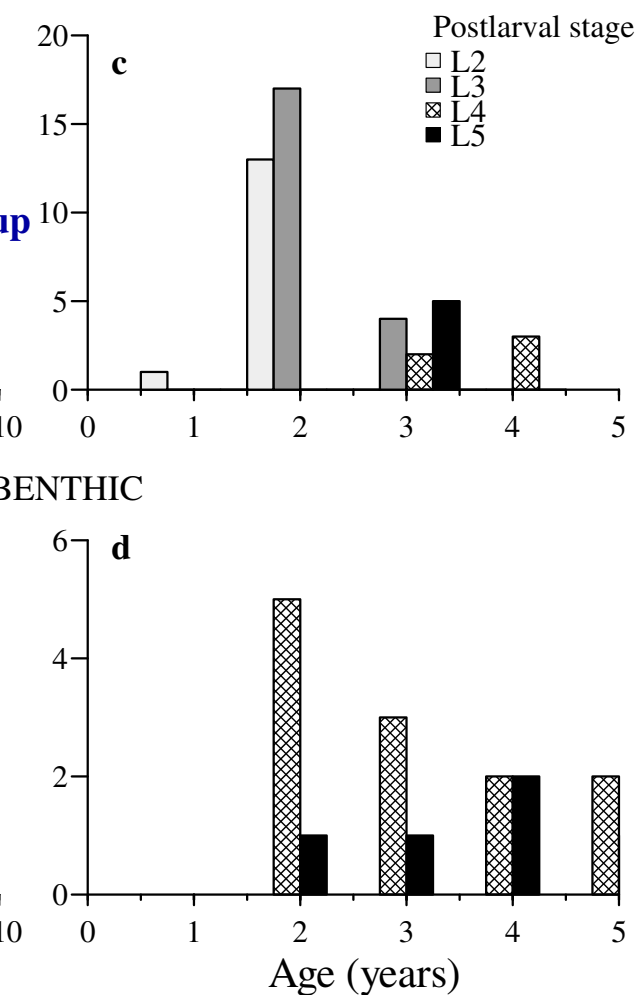

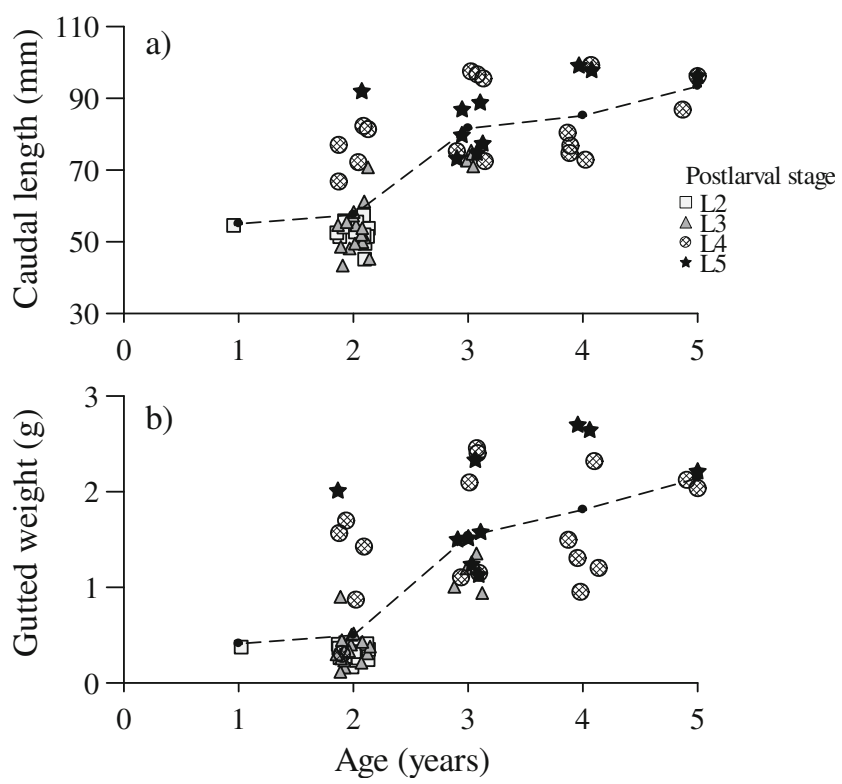

Fig. 6 Caudal length (a) and gutted weight (b) with age of $L$. maculatus postlarvae of different stages. The lines shows the a mean length with age and $\mathbf{b}$ mean weight with age for the entire material

larvae reached about $60 \mathrm{~mm}$ in length at 2 years of age. The length growth slowed down after the postlarvae had reached $\approx 80 \mathrm{~mm}$ and 3 years of age (Fig. 6a). The same pattern was seen for weight with age (Fig. 6b). It increased slightly until the postlarvae reached 2 years of age and $\approx 0.60 \mathrm{~g}$ gutted weight. The weight increase was fast until the postlarvae reached $\approx 1.5 \mathrm{~g}$ and 3 years of age, and subsequently the growth slowed down. This pattern of growth in length and weight was also seen during maturation, which seems to occur when the fish is around 6 years of age (C. Ottesen, unpublished data).

LSI varied with length, weight and age of postlarval stage (Fig. 7). Both stages L2 and L3 showed a continuous increase in LSI with increasing length, weight and age, although their LSI seemed to increase more rapidly with length than with weight. Stage L4 had a declining LSI with increasing length, weight and age. However, the LSI declined rapidly with increasing length (Fig. 7a), while the decline in LSI with increasing weight was rather slow and somewhat steady across the whole weight range (Fig. 7b). The LSI of the smallest L4 specimens was variably high, and they had the highest index measured in this study (12.2\% of gutted weight). However, when L4 specimens reached $\approx 80 \mathrm{~mm}$ in length and $\approx 1.7 \mathrm{~g}$ in weight, the LSI started to decrease with increasing length (Fig. 7a, b). Thus, LSI of the largest L4 specimens was approximately the same as that of the much smaller L2 and L3 specimens. Similarly, at $\approx 3$ years of age, the LSI started to decrease with increasing age of the L4 specimens (Fig. 7c). The L5 specimens had all
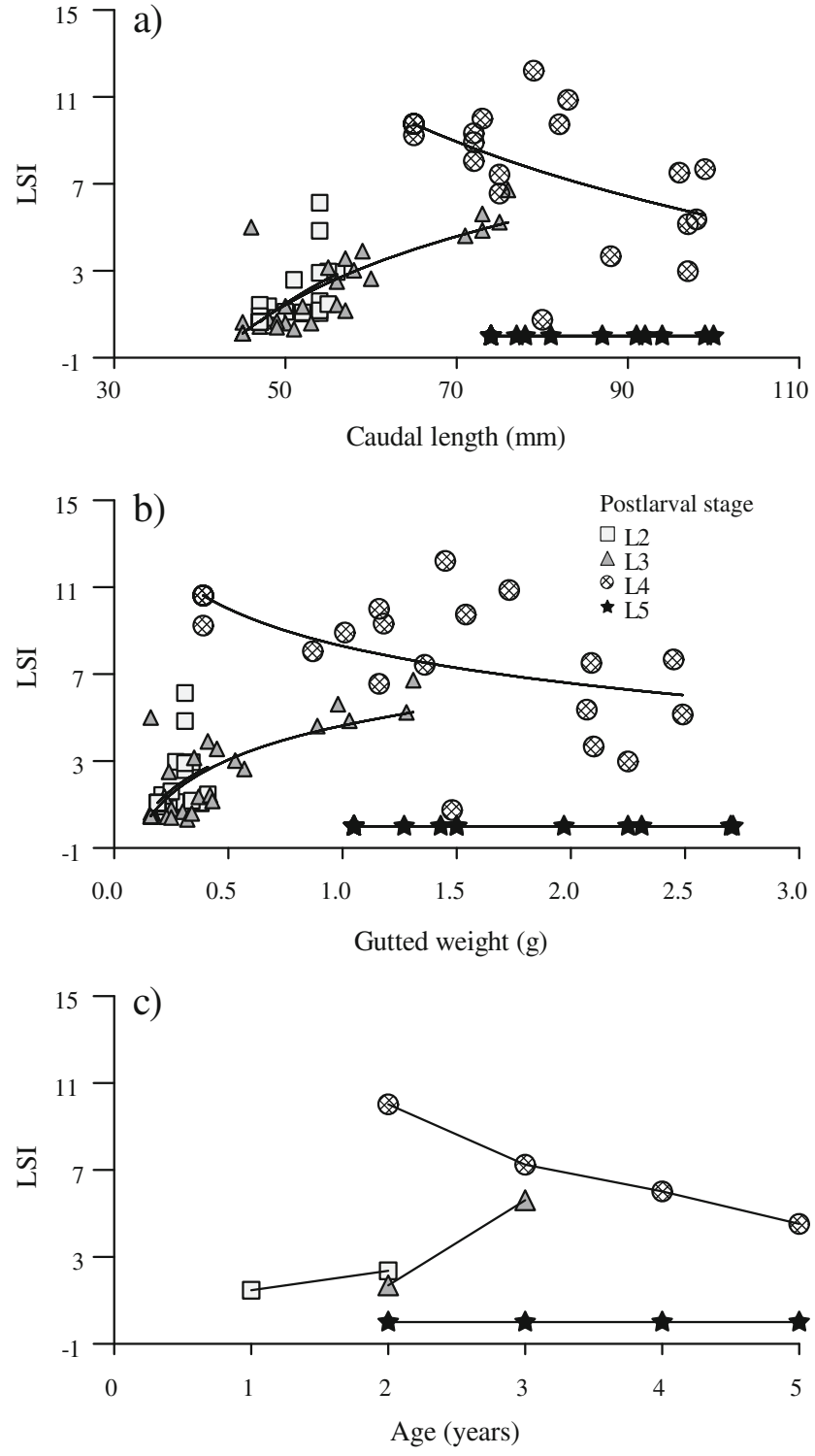

Fig. 7 Lipid sac index (LSI) with a caudal length, b gutted weight and $\mathbf{c}$ age for the different postlarval stages of L. maculatus. Log smoothed regression lines are shown for the LSI with length and gutted weight for each postlarval stage. Median values are used for the illustration of LSI with age (c)

exhausted their lipid storage and therefore all had a LSI of $\approx 0$.

Length-weight relationship and LSI of postlarval groups

The regressions for the two postlarval groups were highly significant $\left(p<0.001, r^{2}\right.$ range $\left.0.801-0.920\right)$ (Table 2). The ANCOVA test of the linear relationship between length and weight indicated difference in growth between the groups $(p=0.010)$, the Pelagic group (L1 and L2) increased faster in weight with length than the Transitional group (L4 and L5) (Table 2, Fig. 8). The Pelagic group had a significantly 
Table 2 Length-weight relationship of $L$. maculatus postlarval groups based on a linear regression analysis of log gutted weight as a function of log caudal length. One outlier was removed from the analysis

\begin{tabular}{llllllrr}
\hline Postlarval groups & $n$ & $a$ & $b$ & SE $b$ & $r^{2}$ & $F$ ratio \\
\hline Pelagic & 36 & -6.76 & 3.64 & 0.31 & 0.80 & 137.12 \\
Transitional & 31 & -5.08 & 2.75 & 0.15 & 0.92 & 332.76
\end{tabular}

steeper slope than the Transitional group. The Pelagic group had a positive allometric growth $(b \approx 3.6)$ and thus increased more rapidly in weight than in length, whereas the Transitional group had a negative allometric growth $(b \approx$ $2.7)$, with more rapid length growth. Specimens between 61 and $71 \mathrm{~mm}$ in length were absent in our material (Fig. 8).

The LSI increased with caudal length (Fig. 9a) and weight (Fig. 9b) for the Pelagic group (L2 and L3) and declined with caudal length and weight for the Transitional group (L4 and L5), although the Transitional group had significantly higher LSI (mean $=4.76 \%$ ) than the Pelagic group (mean $=1.86 \%$, two-sample $t$ test of difference between groups: $p<0.001)$. The LSI of the Transitional group started to decrease when the postlarvae reached about $80 \mathrm{~mm}$ in length and $1.7 \mathrm{~g}$ in weight (Fig. 9). It is evident that the LSI of the smallest specimens of the Transitional group was higher than that of the Pelagic group specimens, while the LSI of the largest specimens of the Transitional group was approximately the same or lower than that of the Pelagic group specimens.

\section{Morphological development}

For the discriminant analysis, only the measurements that contributed to segregate postlarval stages or postlarval groups are included (Table 3). Snout length and

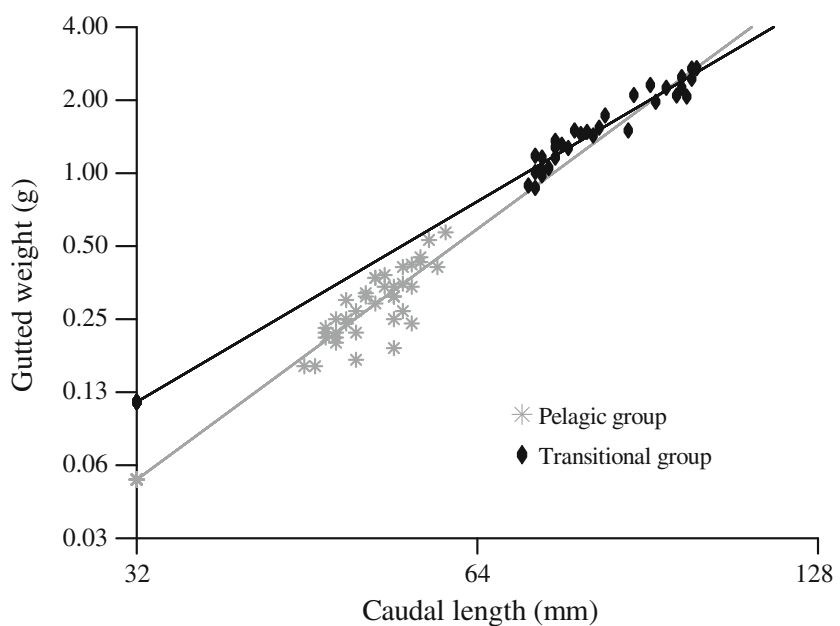

Fig. 8 Log-linear relationship between caudal length and gutted weight of L. maculatus postlarval groups head depth were the most important measurements in distinguishing between the postlarval stages, followed by depth of caudal peduncle, jaw width and eye width, while head depth and dorsal fin length were the most important measurements in discriminating between postlarval groups, followed by interorbital space, pre-anal- and pre-dorsal lengths, eye width, anal fin length and jaw width. All characters increased in size in relation to caudal length from L2 to L5 stage and from the Pelagic group (L2 and L3) to the Transitional group (L4 and L5). The tolerance values show significant correlation between the measurements (Table 3 ). The results from the significance tests given by the discriminant analysis showed that the identified groups were significantly different $(p<0.001)$. The resulting classification matrix showed that $47-87 \%$ of postlarval specimens were placed into correct stages based on the morphometric measure-
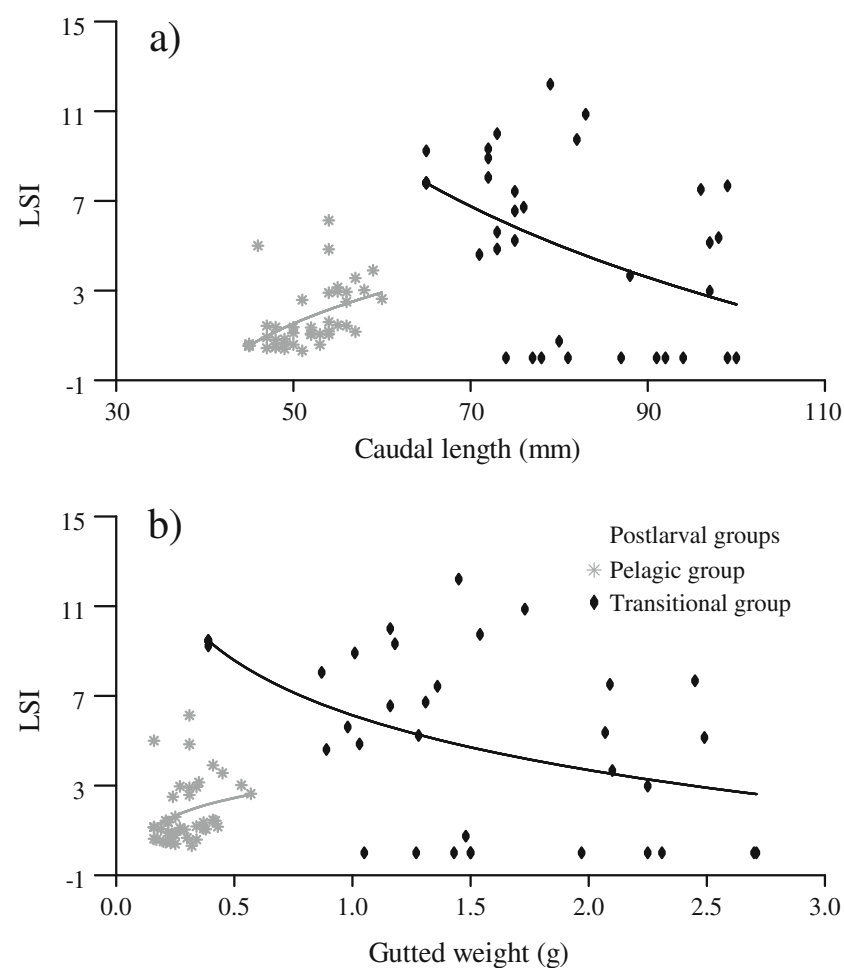

Fig. 9 Lipid sac index (LSI) with a caudal length and b gutted weight for L. maculatus postlarval groups: the Pelagic group and the Transitional group. The lines in (a) and (b) are log smoothed lines for the lipid sac index with length for each postlarval group 
Table 3 Results of the complete model of the discriminant analyses of postlarval stages $(d f 1 / d f 2=42 / 132, F$ ratio $=22.2, p=0.001)$ and postlarval groups $(d f 1 / d f 2=14 / 44, F$ ratio $=9.86, p=0.001)$ of $L$. maculatus

\begin{tabular}{lll}
\hline Parameter & F-to-remove & Tolerance \\
\hline Postlarval stages & & \\
Snout length & 4.4 & 0.51 \\
Head depth & 4.1 & 0.27 \\
Depth of caudal peduncle & 2.7 & 0.70 \\
Jaw width & 2.6 & 0.27 \\
Eye width & 1.9 & 0.36 \\
Postlarval groups & & \\
Head depth & 8.1 & 0.33 \\
Dorsal fin length & 5.2 & 0.14 \\
Interorbital space & 3.7 & 0.22 \\
Pre-anal length & 3.6 & 0.09 \\
Pre-dorsal length & 3.5 & 0.19 \\
Eye width & 3.2 & 0.41 \\
Anal fin length & 2.1 & 0.08 \\
Jaw width & 2.1 & 0.30 \\
\hline
\end{tabular}

The F-to-remove value shows the discriminating value of each parameter, the parameters with the highest F-to-remove value are the most discriminating. The Tolerance values are a measure of the correlation of a particularly parameter with the other parameters (its values range from 0 to 1.0 , the default value is 0.001 ), where a low value means a strong correlation in that parameter to one or more of the other parameters. The tolerance value is a measure of correlation of a particular parameter with the other parameters (its value ranges from 0 to 1.0 ; the default value is 0.001 )

ments, and $97 \%$ of the specimens were placed into correct postlarval groups (Table 4), which confirms that there were morphological differences between the postlarval stages and significant morphological differences between postlarval groups. From the canonical scores presented (Fig. 10), it is seen that the L2 and L3 stages overlap in their morphometric features and that the L4 and L5 stages overlap in their morphometric features, but the L2 and L3 stages seemed to be quite different from the L4 and L5
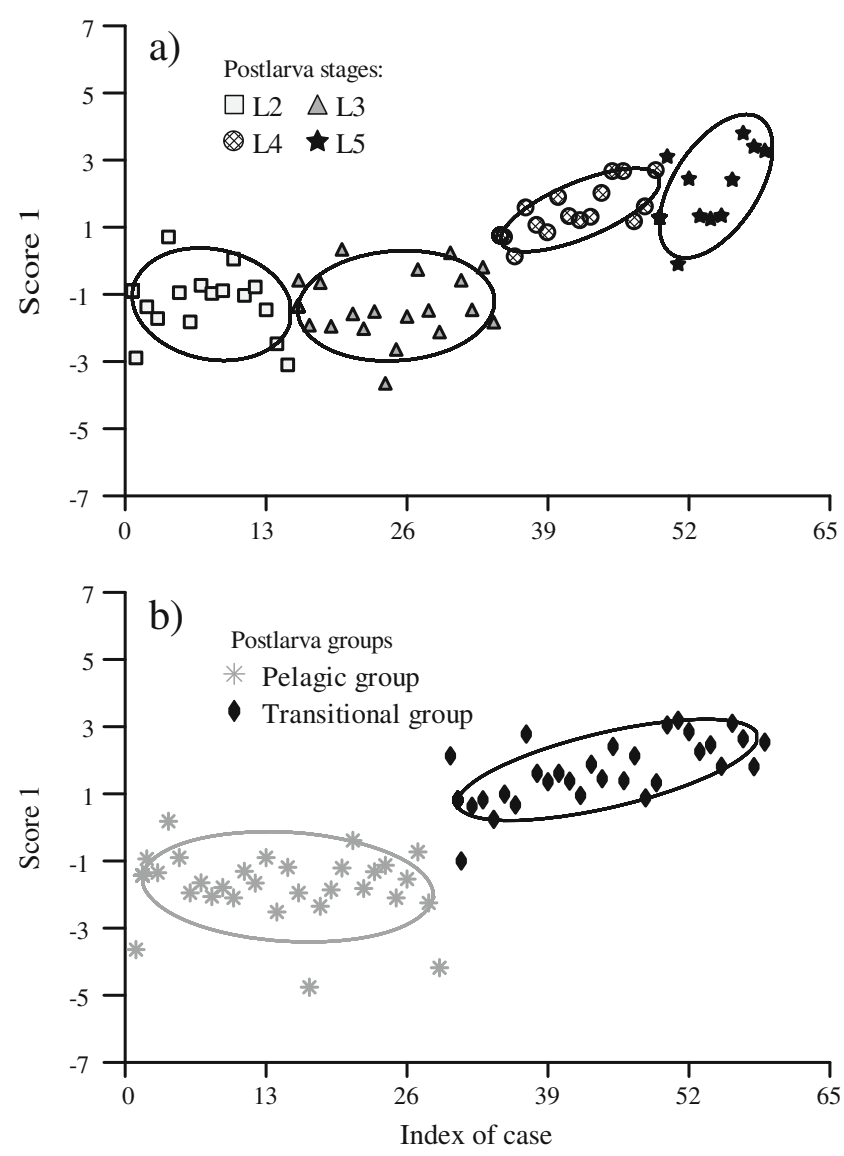

Fig. 10 Canonical scores from discriminant analyses of a postlarval stages and b postlarval groups of L. maculatus The ellipses surrounding the plots are centred on the sample means

stages (Fig. 10a). The Pelagic group and the Transitional group did not seem to overlap in their morphometric features (Fig. 10b).

The morphometric features that were significantly different for postlarval stages were not necessarily those that contributed most in the discriminant analysis (Table 5). This may be due to the high correlation between the measurements. For example, snout length and depth of caudal peduncle was somewhat different but not
Table 4 The classification matrix obtained from discriminant analysis of postlarval stages, and postlarval groups of L. maculatus

The classification matrix shows percentage of specimens that was correctly classified to the stage or group to which they belong using the different morphometric measurements done on the postlarvae in this study

\begin{tabular}{llllll}
\hline Postlarval stage & L2 & L3 & L4 & L5 & \% correct \\
L2 & 11 & 4 & 0 & 0 & 73 \\
L3 & 9 & 9 & 1 & 0 & 47 \\
L4 & 0 & 0 & 13 & 2 & 87 \\
L5 & 1 & 0 & 2 & 7 & 70 \\
Total & 21 & 13 & 16 & 9 & 68 \\
Postlarva group & Pelagic group & & Transitional group & \% correct \\
Pelagic group & 28 & 1 & & 97 \\
Transitional group & 1 & 29 & & 97 \\
Total & 29 & & 30 & 97 \\
\hline
\end{tabular}


Table 5 Morphometric measurements of L. maculatus and their ability to distinguish between different postlarval stages (a) and postlarval groups (b)

\begin{tabular}{|c|c|c|c|c|c|}
\hline \multirow[t]{2}{*}{ Codes } & \multirow[t]{2}{*}{ Morphometric measurement } & \multicolumn{2}{|c|}{ A. Postlarval stages (Kruskal-Wallis) } & \multicolumn{2}{|c|}{ B. Postlarval groups (two-sample $t$ test) } \\
\hline & & Test statistic & Probability & $t$ value & Probability \\
\hline $\mathrm{A}, \mathrm{B}$ & Head depth & 38.51 & $<0.001$ & -9.96 & $<0.001$ \\
\hline $\mathrm{A}, \mathrm{B}$ & Jaw width & 14.62 & $<0.001$ & -4.22 & $<0.001$ \\
\hline $\mathrm{A}, \mathrm{B}$ & Eye width & 18.0 & $<0.001$ & $-5,27$ & $<0.001$ \\
\hline NONE & Eye length & 23.74 & $<0.001$ & -6.04 & $<0.001$ \\
\hline $\mathrm{B}$ & Interorbital space & 32.91 & $<0.001$ & -3.72 & $<0.001$ \\
\hline NONE & Body depth & 21.57 & $<0.001$ & -4.68 & $<0.001$ \\
\hline $\mathrm{B}$ & Length of dorsal fin & 11.59 & 0.010 & 3.25 & $<0.001$ \\
\hline $\mathrm{A}$ & Snout length & 10.91 & 0.010 & 2.89 & 0.010 \\
\hline $\mathrm{B}$ & Pre-anal length & 4.59 & 0.210 & 2.82 & 0.010 \\
\hline NONE & Length of caudal fin & 3.19 & 0.360 & 0.87 & 0.390 \\
\hline $\mathrm{B}$ & Pre-dorsal length & 3.29 & 0.350 & 0.77 & 0.450 \\
\hline NONE & Head length & 2.38 & 0.500 & -0.24 & 0.810 \\
\hline A & Depth of caudal peduncle & 6.92 & 0.070 & 0.18 & 0.860 \\
\hline $\mathrm{B}$ & Length of anal fin & 0.35 & 0.950 & 0.42 & 0.680 \\
\hline
\end{tabular}

Two significant tests were used to test whether each morphometric measurement was significantly different between postlarval stages or groups. Kruskal-Wallis test was used for postlarval stages while a two-sample $t$ test was used for postlarval groups. The Codes indicate which morphometric measurement that was significant in the discriminant analyses of $A$ postlarval stages and $B$ postlarval groups, whereas $N O N E$ indicates measurement that was insignificant in the discriminant analyses

significantly so between postlarval stages, while depth of body was significantly different both between postlarval stages and postlarval groups. From the results of the morphometric analyses, it seems that the characters that differed most between postlarval stages and groups were those that are significant in feeding success, prey change and habitat change of the postlarva (e.g. more powerful head, bigger mouth and jaws, bigger eyes, longer fins for better manoeuvrability, and a more powerful body).

\section{Discussion}

Length and age distribution

We found five different postlarval stages of L. maculatus, and four stages were processed in our analyses. The smallest stages (L1-L3) were only found in the pelagic environment, the largest (L4-L5) were in a transitional phase and found both in the pelagic environment and at the bottom. The length and age distribution of $L$. maculatus postlarvae showed a relatively large size- and age-range in the pelagic environment. Our results suggest that $L$. maculatus larvae grow and develop the first 2-3 years in the pelagic environment and then descend to the bottom as late postlarvae or early juveniles. This seems to be in contrast to most other benthic fishes, which only have a short pelagic larval stage in conjunction with the zooplankton bloom. All the benthic specimens of $L$. maculatus postlarvae were $>70 \mathrm{~mm}$ and $\geq 2$ years. Although the age distribution was more even in the postlarval samples, there was a notable lack of specimens between 61 and $71 \mathrm{~mm}$ in length, resulting in two peaks in the length distribution: one between $\approx 40$ and $60 \mathrm{~mm}$ (pelagic postlarvae) and one between $\approx 70$ and $100 \mathrm{~mm}$ (transitional postlarvae). Similar size-classes were found in arctic shanny (Stichaeus punctatus) from Nuvuk Islands, Canada, where the samples were dominated by two size-classes (Keats et al. 1993). These size-classes corresponded to specimens that were $2+$ and $3+$ years and $55 \mathrm{~mm}$ long and to fish aged 6 and older at $125 \mathrm{~mm}$ in length, although fish aged 4-5 years were absent from the samples (Keats et al. 1993). The biomodal size- and age distributions were attributed to variable and irregular recruitment in the population. Variable recruitment could explain the absence of fishes of $61-71 \mathrm{~mm}$ in length from our samples, although there was no concurrent absence of age groups. This may also be a consequence of high predation pressure on this size-range when they first attempt to settle at the bottom, or variation in habitat preference (e.g. depth and temperature) between size groups, as reported for longfin prickleback (Bryozoichthys lysimus) (Tokranov and Orlov 2004), which influences sampling of postlarval size-groups. 
Size-at-age and LSI

The results showed a slow increase in size from ages 1 to 2 , rapid increase until the age of 3 , and then slow increase thereafter. The most plausible explanation for this result is differences between larval developmental stages, feeding success, habitat change and LSI. The slow increase in size from 1 to 2 years of age may be misleading since we only obtained a few specimens of $<2$ years of age. However, a slow larval growth has been reported in arctic shanny (Stichaeus punctatus) (Keats et al. 1993), long shanny (Stichaeus grigorjewi) (Kyushin 1990) and Opisthocentrus zonope from cold waters (Gnyubkina and Markevich 2008). Our results may reflect hatching during the winter and thus slow growth for the 0- to 1-year-old larvae due to low temperatures and low availability of prey. The LSI of the smallest postlarva (L2 stage) increased from 1 to 2 years of age and between 2 and 3 years (L3-early L4 stages), and as the LSI reached its peak the postlarvae increased rapidly in size with age. When they reached 3 years $(80 \mathrm{~mm}, 1.7 \mathrm{~g})$, the growth in size with age slowed down. At the same age and size, the LSI started to decrease and the lipid sac was absorbed and disappeared as the pelagic postlarvae developed into benthic juveniles. As the lipid sac diminishes in size when the larvae are at the late L4 stage, they become increasingly dependent upon securing enough energy for their metabolic processes and can no longer rely on the energy reserve. At the same time, they settle on the bottom and switch to different types of prey. They will also encounter other predators and have to learn to avoid them. Thus, increased energy expenses associated with the habitat shift are expected to result in reduced growth.

Length-weight relationship and LSI of postlarval groups

In contrast to increase in size with age, it was the smallest size-group (the Pelagic group) that had the fastest growth in weight. The Pelagic group (L2-L3 stages, $\approx 40-60 \mathrm{~mm}$ in length) had a positive asymptotic growth $(b \approx 3.6)$, thus becoming stouter with length, while the Transitional group (L4-L5 stages, $\approx 70-100 \mathrm{~mm}$ ) had a negative allometric growth $(b \approx 2.7)$, thus becoming thinner with length. The differences in $\mathrm{s}$ in length-weight relationship and growth between the Pelagic group and the Transitional group are likely related to the decreasing LSI of the Transitional group, and the different life modes of the two groups. Differences in habitat and abiotic factors (e.g. temperature and salinity) likely influenced the length-weight relationships. Transitional postlarvae might not obtain as much energy for tissue growth as the Pelagic group. As was evident from the size-at-age results, the growth slows down in the oldest and largest postlarvae. It should also be mentioned that eel-like larvae swim slowly, have manoeuvring problems and rarely attack the same prey twice (Froese 1990). Therefore, they face challenges in obtaining sufficient food for rapid growth when they no longer can rely on stored lipid reserves. Comparatively, pelagic postlarvae still have large lipid stores that they can rely on if the prey abundance is low. As we have seen, the increase in size with age seems to be slow for the smallest specimens. However, specimens in the Pelagic group must also allocate some energy for growth as their small size makes them available to a large range of predators. Also, eel-shaped fish larvae do not swim constantly but alternate between active swimming when feeding and passive gliding (Froese 1990). This is considered to be energetically advantageous (Froese 1990) and thus enables the pelagic postlarvae to sustain their lipid reserves through the winter when zooplankton is scarce. The low temperature of the high arctic waters also slows down the metabolism so that the postlarvae can save energy for growth and survival.

\section{Morphological development}

Large morphological changes occurred between the L3 and L4 stages. The L2-L3 and the L4-L5 stages, respectively, overlapped in morphological features, but the L2-L3 stages did not overlap much with the L4-L5 stages. The L3 stage is the one with most specimens misclassified to other stages by the discriminant analysis. Half the specimens were misclassified as L2 stages, which indicates that the L3 specimens we obtained were intermediate between L2 and L3 and that the lack of specimens in the 61-71 mm lengthgroup might represent the late L3 stage. The high misclassification of L3 specimens in the discriminant analysis could also be contributed to the subjective classification of the larval stages. It may be that L2 and L3 should have been classified as one stage rather than separate stages. The absence of the $61-71 \mathrm{~mm}$ size-group is one probable reason for the gap between the L2-L3 stages and L4-L5 stages. The classification of specimens into postlarval groups was almost $100 \%$ correct and thus the groups did not overlap. This supports the idea that the absent $61-71 \mathrm{~mm}$ specimens represent a morphological step in the development. It also supports that at around $80 \mathrm{~mm}$ (the size-range represented by the Transitional group), L. maculatus changes from a pelagic life mode to a benthic life mode and starts to develop into juveniles. As the postlarvae develop from L2-L3 stages (the Pelagic group) into L4-L5 stages (the Transitional group), they become stouter with a significantly deeper head and body, larger eyes, and jaws. This likely reflects the habitat and life mode change between the Pelagic group and the Transitional group. The L2-L3 stages are translucent, which 
makes them difficult to detect in the pelagic habitat. As they grow into L4-L5 stages, they become more pigmented and thus develop a benthic camouflage. The wider jaws enable them to exploit a larger range of prey, and the larger eyes might make them more efficient predators in the benthic habitat. The more powerful body enables them to better avoid benthic predators.

\section{Conclusions}

The L. maculatus postlarva has a unique lipid sac that enables them to store energy reserves when food is available in the pelagic that they can survive on during the winter. The lipid sac is likely an adaptation for survival in high Arctic waters. It enables the slow growing $L$. maculatus postlarvae to live in the pelagic zone, where there a fewer predators, during the first $2-3$ years of their life. The results of age and size distribution, length-at-age, growth and LSI of postlarval stages indicate that the transition between pelagic and a benthic life mode happens when the postlarva reaches approximately $80 \mathrm{~mm}$ in length at 3 years of age. At this time, their lipid sac is absorbed, its body becomes more densely pigmented and changes into a deeper more powerful body with larger jaws and eyes. This presumably increases their survival in the benthic habitat. Although there are descriptions of $L$. maculatus postlarvae from other areas of their distributional range, the lipid sac does not seem to be present in postlarvae from these areas. It may be that the lipid sac is a trait that has evolved only in some high Arctic populations, such as the population in Svalbard waters.

\section{Future research}

As L. maculatus is an ecologically important species in arctic waters, more work needs to be done to reveal different aspects of its development and life history. Laboratory rearing of L. maculatus should be done to study and describe its embryonic development, larval size at hatching and morphology, development of its prolarva and development from prolarva to postlarva. If there is a yolk sac stage, the duration from the time of yolk absorption to development of lipid sac should also be studied, as well as the size at first feeding and the impact of feeding on the development of the lipid sac. We further suggest study of morphological traits of postlarvae from the whole distribution range of $L$. maculatus to examine if the lipid sac of the postlarvae is present in many populations or if it is a trait that have evolved only in some high arctic populations. Such a study should include morphometric measurements of the postlarvae, its lipid sac if present, and lipid composition in different populations, as well as DNA studies.
Acknowledgements This publication was originally presented at the Arctic Frontiers Conference in Tromsø, January 2010. The support and initiative of ARCTOS and Arctic Frontiers are gratefully acknowledged. This work is supported by Statoil and ARCTOS. We also acknowledge the TUNU-Programme (University of Tromsø) for the opportunity to sample material. We would like to thank the crew of RV Jan Mayen for their assistance.

Open Access This article is distributed under the terms of the Creative Commons Attribution Noncommercial License which permits any noncommercial use, distribution, and reproduction in any medium, provided the original author(s) and source are credited.

\section{References}

Andriyashev AP (1954) Fishes of the northern seas of the U.S.S.R. Keys to the fauna of the U.S.S.R. Published by the Zoological Institute of the U.S.S.R. Academy of Sciences. No. 53. Translated from Russian by the Israel Program for Scientific Translations, Jerusalem 1964, pp 266-269

Barrett RT (2002) Atlantic puffin Fratercula arctica and common guillemot Uria aalge chick diet and growth as indicators of fish stocks in the Barents Sea. Mar Ecol Prog Ser 230:275267

Baylis JR (1981) The evolution of parental care in fishes, with reference to Darwin's rule of male sexual selection. Environ Biol Fish 6:223-251

Byrkjedal I, Høines $\AA$ (2007) Distribution of demersal fish in the south-western Barents Sea. Polar Res 26:135-151

C.A.R.E. (Committee of Age Reading Experts) (2000) Manual on generalised age determination procedures for groundfish. Web-link: http://care.psmfc.org/docs/CareManual2006.pdf

Christansen JS, Fevolden SE, Karamushko OV, Karamushko LI (1998) Maternal output in polar fish reproduction. In: di Prisco G, Pisano E, Clarke A (eds) Fishes of Antarctica: a biological overview. Springer, Milano, pp 41-52

Clarke A, Doherty N, DeVries AL, Eastman JT (1984) Lipid content and composition of three species of Antarctic fish in relation to buoyancy. Polar Biol 3:77-83

Fahay MP (n.d.) Early stages of fishes in the Western North Atlantic Ocean (Davis Strait, Southern Greenland and Flemish Cap to Cape Hatteras). Volume One: Acipenseriformes through Syngnathiformes. ISBN 0-9689167-4-x. Web-link: http://archive.nafo. int/open/fahay/front-vol1.pdf

Falk-Petersen S, Falk-Petersen I-B, Sargent JR (1986) Structure and function of an unusual lipid storage organ in the arctic fish Lumpenus maculatus Fries. Sarsia 71:1-6

Fries BF (1838) Ichthyologiska bidrag till Skandinaviens fauna. Kongl Vet Acad Handl Stockholm, for 1837:23-58

Froese R (1990) Growth strategies of fish larvae. ICES C.M./L:91:1-20

Gill TN (1864) Note on the family of stichaeoids. Proc Acad Nat Sci Philadelphia 16:208-211

Gnyubkina VP, Markevich AI (2008) Reproduction and development of Pholis picta (Perciformes: Pholidae) and Opisthocentrus zonope (Stichaeidae). J Ichthyol 48:525-532

Gross MR, Shine R (1981) Parental care and mode of fertilization in ectothermic vertebrates. Evolution 35:775-793

Hubbs CL (1943) Terminology of early stages of fishes. Copeia 43:260

Keats DW, Steele DH, Green JM, Martel GM (1993) Diet and population size structure of the Arctic shanny, Stichaeus punctatus (Pisces: Stichaeidae), at sites in eastern Newfoundland and the eastern Arctic. Environ Biol Fish 37:173-180 
Kyushin K (1990) Embryonic development and larvae of long shanny, Stichaeus grigorjewi Herzenstein. Bull Fac Fish Hokkaido Univ 41:13-17

Labansen AL, Lydersen C, Haug T, Kovacs KM (2007) Spring diet of ringed seals (Phoca hispida) from northwestern Spitsbergen, Norway. ICES J Mar Sci 64:1246-1256

Mecklenburg CW, Sheiko, BA (2004) Annotated checklist of fishes: Family Stichaeidae Gill 1864, pricklebacks. An electronic journal published by the California Academy of Sciences ISSN 1545150X (CD-ROM). Web-link: http://research.calacademy.org/files/ Departments/ichthyology/Stichaeidae.pdf

Murzina SA, Falk-Petersen S, Nemova N (2008) Lipids in the arctic fish, Leptoclinus maculatus larvae. Abstract from conference: Chemistry and Physics of Lipids 154S:S21-S23

Murzina SA, Nemova NN, Nefedova ZA, Falk-Petersen S (2010) Effects of ecological conditions on lipid composition of the liver and muscles in the daubed shanny, Leptoclinus maculatus. Russ J Ecol 41:51-54
Nilssen KT, Lindstrøm U (2005) Use and selection of prey by harp seals during summer in the northern Barents Sea. ICES, CM 2005/R:10

Pethon P (2005) Aschehougs store fiskebok, 5th edn. Aschehoug, pp 362-363

Phleger CF (1998) Buoyancy in marine fishes: direct and indirect role of lipids. Am Zool 38:321-330

Rose GA (2005) On distributional responses to North Atlantic fish to climate change. ICES J Mar Sci 62:1360-1374

Sakshaug E, Bjørge A, Gulliksen B, Loeng H, Mehlum F (1994) Økosystem Barentshavet. Norges forskningsråd, Universitetsforlaget, Oslo

Tokranov AM, Orlov AM (2004) Biology of longfin prickleback Bryozoichthys lysimus (Stichaeidae) from Pacific waters of northern Kuril Islands. J Ichthyol 44:366-370

Watanuki Y, Naito Y, Schauer J (1992) Chick diet and daily activity of Common murres and Black-legged kittiwakes at Bluff seabird colony, Norton Sound. Alaska Proc NIPR Symp Polar Biol 5:98104 